\title{
Erratum to: Post-orogenic shoshonitic magmas of the Yzerfontein pluton, South Africa: the 'smoking gun' of mantle melting and crustal growth during Cape granite genesis?
}

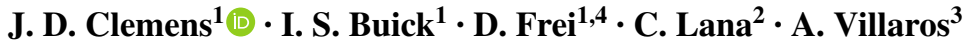

Published online: 14 September 2017

(c) Springer-Verlag GmbH Germany 2017

\section{Erratum to: Contrib Mineral Petrol (2017) 172:72 DOI 10.1007/s00410-017-1390-9}

The published version of the original paper contained a $\mathrm{Sr}$ isotope analysis of Hornblende-pyroxene quartz monzodiorite sample $\mathrm{H} 25$, from the shoshonitic part of the Cambrian Yzerfontein pluton on the West Coast in South Africa. The value of ${ }^{87} \mathrm{Sr} /{ }^{86} \mathrm{Sr}$, calculated at our newly determined $\mathrm{U}-\mathrm{Pb}$ zircon age of $535 \mathrm{Ma}$, was given as $0.70885 \pm 2(2 \sigma)$. In the paper, this was reported as an anomalously high value and we hypothesised that this might have been due to the crustal component of this particular magma having been somewhat more radiogenic than for the rest of the shoshonitic samples from the Yzerfontein pluton.

We emphasise that the isotopic and elemental analyses were carried out on the same solutions. Nothing in the $\mathrm{Rb} / \mathrm{Sr}$ ratio indicated accidental contamination of the sample, and nothing in the isotope results suggested analytical problems. However, this result was sufficiently surprising that we provided AEON Labs (UCT) with a second aliquot to dissolve and analyse. The redetermined value of ${ }^{87} \mathrm{Sr} /{ }^{86} \mathrm{Sr}_{535 \mathrm{Ma}}$ is $0.70506 \pm 2$, which is very similar to all the other determinations for the shoshonitic rocks of the pluton. Although we remain unable to explain the original result, we believe it to have been erroneous and that the correct initial Sr isotope ratio of sample $\mathrm{H} 25$ is 0.70506 . Accordingly, we present a revised Table 1, showing the Sr and $\mathrm{Nd}$ isotope data, with the correction, and a revised version of Figs. 6 and 13 in the original paper, as Figs. 1 and 2 here, with the correct value for $\mathrm{H} 25$ plotted. This amendment has no impact on the main conclusions of the original paper.

The online version of the original article can be found under doi:10.1007/s00410-017-1390-9.

\section{J. D. Clemens}

jclemens@sun.ac.za

1 Department of Earth Sciences, Stellenbosch University, Private Bag X1, Matieland 7602, South Africa

2 Departamento de Geologia, Escola de Minas, Universidade Federal de Ouro Preto, Morro do Cruzeiro, 35400-000 Ouro Preto, Minas Gerais, Brazil

3 Université d'Orleans, ISTO, UMR 7327, 45071 Orleans, France

4 Present Address: Department of Earth Science, University of the Western Cape, Private Bag X17, Bellville 7535, South Africa 
Table 1 Whole-rock $\mathrm{Rb}-\mathrm{Sr}$ and $\mathrm{Sm}-\mathrm{Nd}$ isotope data for Yzerfontein samples

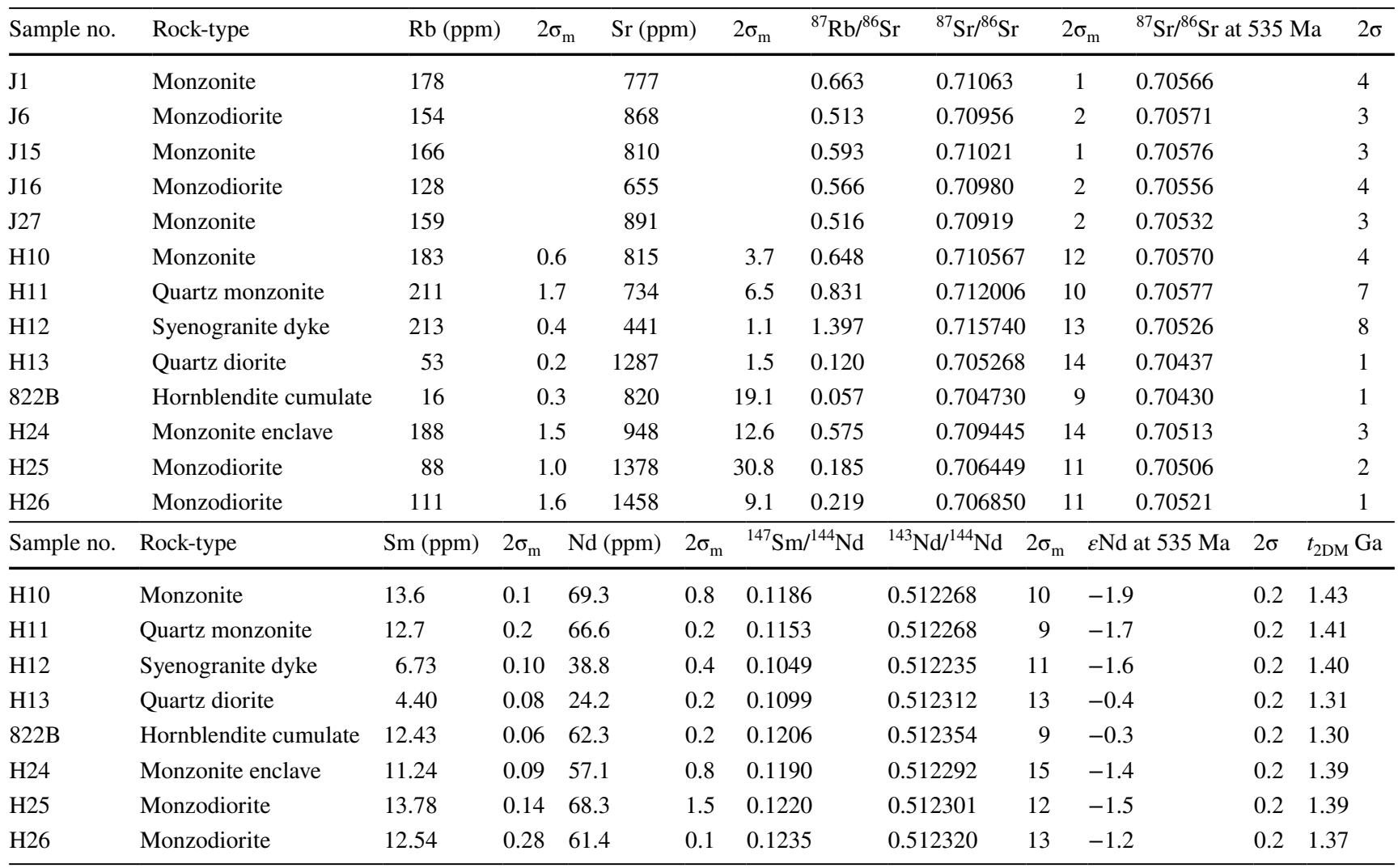

Samples J1, J6, J15, J16 and J27 from Jordaan et al. (1995), with $2 \sigma_{\mathrm{m}}$ errors of $0.2 \mathrm{ppm}$ assumed for Rb and Sr concentrations Samples H10, H11, H12, H13 822B, H24, H25 and H26 from present work 

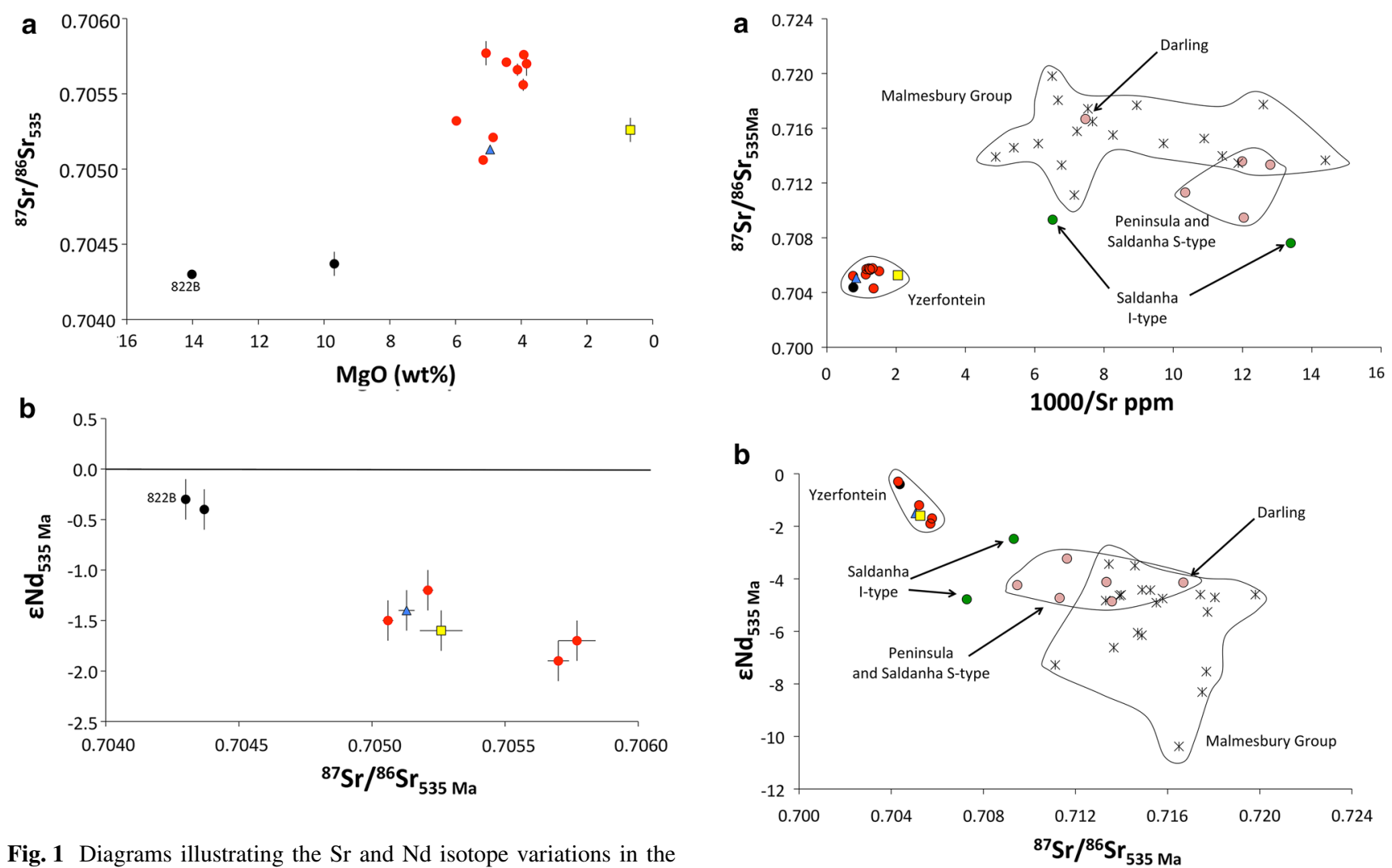

Fig. 1 Diagrams illustrating the $\mathrm{Sr}$ and $\mathrm{Nd}$ isotope variations in the rocks of the Yzerfontein pluton, a initial ${ }^{87} \mathrm{Sr} /{ }^{86} \mathrm{Sr}$ plotted against $\mathrm{MgO}$ (wt\%), b $\varepsilon \mathrm{Nd}_{t}$ plotted against initial ${ }^{87} \mathrm{Sr} /{ }^{86} \mathrm{Sr}$. The colour coding is as given in Fig. 4, with the hornblendite cumulate rock (822b) labelled. In a, the $2 \sigma$ error bars for initial ${ }^{87} \mathrm{Sr} /{ }^{86} \mathrm{Sr}$ are plotted but are all smaller than the plot symbols. The same is true in $\mathbf{b}$, except for the micromonzogranite sample H12 (yellow square). See the original paper for a discussion of these plots

Fig. 2 Isotope plots illustrating the relationships between the rocks of the Yzerfontein pluton, the Cape Granite Suite granitic rocks (CGS) S-type (pink dots) and I-type (dark green dots) and the metasedimentary rocks of the Malmesbury Group (stars), with all isotope ratios normalised to the new $535 \mathrm{Ma}$ age for the Yzerfontein pluton, a Sr isotope mixing plot, with initial ${ }^{87} \mathrm{Sr} /{ }^{86} \mathrm{Sr}$ plotted against $1000 / \mathrm{Sr}, \mathbf{b}$ isotope correlation diagram, with $\varepsilon \mathrm{Nd}_{t}$ plotted against initial ${ }^{87} \mathrm{Sr} /{ }^{86} \mathrm{Sr}$. See the original paper for data provenance and discussion 